\title{
A NOÇÃO DE EXPERIÊNCIA NO JOVEM WALTER BENJAMIN E SUA CRÍTICA A DESCARTES E KANT
}

\author{
Camila Vieira da Silva ${ }^{1}$
}

\begin{abstract}
RESUMO
Verificar o conceito de experiência nos escritos de juventude de Walter Benjamin e seu contraponto em relação às teorias que foram desenvolvidas ao longo da história da filosofia, especialmente por Descartes e Kant. Desde a separação entre o inteligível e o sensível em Platão até o preceito kantiano das condições de possibilidade para todo conhecimento, a experiência foi conceituada de forma diferente ao que propõe Benjamin. Se para Kant, o conhecimento e a experiência são elaborados a partir de conceitos a priori no sujeito transcendental; para Benjamin, a experiência não pode ser traduzida em conceitos, pois não é mero resultado de processos de abstração.
\end{abstract}

Palavras-chave: Experiência. Walter Benjamin. História da filosofia. Ciência. Conhecimento.

\section{THE NOTION OF EXPERIENCE IN THE YOUNG WALTER BENJAMIN AND HIS CRITIQUE OF DESCARTES AND KANT}

\begin{abstract}
This article seeks to understand the notion of experience in the youth writings of Walter Benjamin and his counterpoint in relation to theories developed throughout the history of philosophy, especially Descartes and Kant. Since the separation between the intelligible and the sensible of Plato to Kant's precept of the conditions of possibility for all knowledge, the experience was conceptualized differently to Benjamin proposes that way. To Kant, knowledge and experience are drawn from a priori concepts in the subject; for Benjamin, the experience can not be translated into concepts, it is not merely the result of processes of abstraction.
\end{abstract}

Keywords: Experience. Walter Benjamin. History of philosophy. Science. Knowledge.

\section{A experiência e seus vastos significados}

Com o desenvolvimento da técnica científica, a noção de experiência na modernidade é comumente relacionada ao processo que, por meio de um método científico, busca demonstrações racionais de determinado fenômeno natural, a partir da sua observação sob condições pré-estabelecidas. Apesar desta concepção racionalista e tecnicista em que o modelo por excelência é o cálculo matemático e a

${ }^{1}$ Camila Vieira é Graduada em Filosofia pela UECE 
procura de leis gerais e universais, o conceito de experiência no percurso da história da filosofia é muito amplo e adquiriu significados vastos que não se resumem apenas ao procedimento científico. Na Filosofia, experiência pode ser o conhecimento empírico obtido por meio dos sentidos ou pela apreensão sensível dos objetos, como algo anterior a qualquer reflexão.

Para a filosofia de Platão, a separação entre o mundo sensível e o mundo inteligível equivale à cisão entre experiência e razão. No livro VII da República, tudo o que é apreendido via experiência por meio dos sentidos é fonte de engano e erro, como sombras projetadas na parede da caverna. Elas parecem reais aos prisioneiros da caverna, mas não são verdadeiras como a luz do sol que indica a razão. Platão compara a libertação do homem para o mundo fora da caverna à elevação da alma ao mundo inteligível. "A ideia do bem é a última a ser apreendida, e com dificuldade, mas não se pode apreendê-la sem concluir que ela é a causa de tudo o que de reto e belo existe"2. Para Platão, a salvação do ser humano só é possível pela adequação da alma ao logos transcendente do Bem.

Já para Aristóteles, a experiência humana é o único transcendental a que temos acesso, pois é o que somos enquanto propriamente humanos. Tudo o que há em nosso intelecto provém dos sentidos e, por meio do conhecimento empírico, é possível encontrar bases sólidas para as investigações filosóficas. No primeiro livro da Metafisica, Aristóteles fala da experiência a partir do desejo humano de conhecer. A experiência é uma etapa da aquisição do conhecimento: várias lembranças de uma mesma coisa constituem a experiência, independente de sua veracidade pelo intelecto.

Segundo Aristóteles, a experiência é apreensão ou conhecimento do singular, pois possibilita a confirmação dos juízos sobre a realidade por meio da verificação sensível. Já a arte e a ciência, são conhecimentos universais, que pressupõem o singular. "Quem possua a noção sem a experiência, e conheça o universal ignorando o particular nele contido, enganar-se-á muitas vezes"3.

$\mathrm{Na}$ passagem da Idade Média para a Idade Moderna, começa a existir um questionamento do valor da experiência entendido pela tradição ocidental. A revolução científica afirma um novo indivíduo, capaz de fazer e fabricar coisas do mundo - algo que implica como consequência outra noção de conhecimento, em

\footnotetext{
2 PLATÃO. A República. São Paulo: Nova Cultural, 1997, p. 228.
}

${ }^{3}$ ARISTÓTELES. Metafísica. São Paulo: Abril, 1973, p. 212. 
que a verdade e a realidade não são dadas de imediato. No pensamento grego e medieval, o real se revelava por si mesmo; a verdade era aletheia (desvelamento do ser) e cabia às faculdades humanas reconhecer por meio da razão. A modernidade questiona este desvelamento, pondo em xeque ou dúvida a relação entre sujeito e objeto.

René Descartes introduz a dúvida metódica, que pressupõe que a subjetividade racional pode conhecer apenas aquilo que ela mesma produz, sendo o more geometrico o campo exemplar deste conhecimento. O que os homens têm em comum são suas faculdades racionais e a experiência nada mais é que a elaboração e a execução de métodos rígidos e seguros de conhecimento.

Em vez de priorizar o racionalismo como faz Descartes, o empirista David Hume procura dar mais ênfase à experiência científica na busca pela verdade. Em Investigações Acerca do Entendimento Humano, Hume ${ }^{4}$ afirma ser seu objetivo criar um método para a filosofia que "não decorresse da invenção, mas da experiência", utilizando-se do "espírito de exatidão e do raciocínio".

A existência de qualquer ser somente pode ser provada mediante argumentos derivados de sua causa ou de seu efeito, e estes argumentos se fundam inteiramente na experiência. (...) É unicamente a experiência que nos ensina a natureza e os limites da causa e do efeito, e permite-nos inferir a existência de um objeto partindo de um outro ${ }^{5}$.

Quem melhor ilustra a desconfiança na experiência concebida no sentido tradicional é Francis Bacon. Para este filósofo, existe uma diferença abissal entre a experiência que ocorre de forma espontânea pelos sentidos como acreditavam os antigos e a que é buscada deliberadamente por meio de axiomas pela ciência (a isto Bacon chama de experimento). O conhecimento de algo não estaria mais na autoridade narrativa daquele que experimentou determinada coisa, mas na relação entre a dedução axiomática, feita pelo sujeito, e na sua comprovação por meio dos experimentos, que se dá fora do sujeito. Sobre esta distinção, afirma Bacon:

Mas a experiência comum não é mais que uma vassoura desmantelada, um
proceder tateante como o de quem perambulasse à noite na esperança de
atinar com a estrada certa, enquanto seria mais útil e prudente esperar pelo
dia ou acender um lume, e só então pôr-se a caminho. A verdadeira ordem
da experiência começa por acender o lume; com este, em seguida, aclara o
caminho, iniciando pela experiência bem disposta e ponderada e não por

${ }^{4}$ HUME, D. Investigações acerca do entendimento humano. Rio de Janeiro: Companhia Editora Nacional; São Paulo: Edusp, 1972, p. 13.

5 Idem, p. 148. 
aquela descontínua e às avessas; primeiro deduz os axiomas e depois procede a novos experimentos ${ }^{6}$.

É a partir dessa desconfiança que a ciência moderna instaura o tecnicismo, que confia a experiência aos instrumentos, às regras, aos métodos, exigindo exatidão e rigor quantitativos. A experiência passa a ser sinônimo de experimento, compatível com a certeza do cálculo e das leis científicas.

\section{Crítica de Benjamin a Descartes e Kant}

Nas leituras que Benjamin empreende da obra de Descartes, existe uma reflexão profunda sobre os limites do racionalismo, bem como de suas possibilidades e consequências para a filosofia. No texto "Questões introdutórias de crítica do conhecimento" de seu Origem do Drama Barroco Alemão, Benjamin explica como a doutrina filosófica funda-se na codificação histórica e jamais pode ser invocada more geometrico. Para Benjamin, a verdade não comunica pela enunciação - algo que apreenderia o exato por demonstração científica. Pelo contrário, a verdade do conhecimento só se manifesta quando aquilo que se pretende enunciar estiver destruído.

Quanto mais claramente a matemática demonstra que a eliminação total do problema da representação reivindicada por qualquer sistema didático eficaz é o sinal do conhecimento genuíno, mais decisivamente ela renuncia àquela esfera da verdade visada pela linguagem ${ }^{7}$.

De acordo com Benjamin, a filosofia que permanece fiel à sua forma como representação da verdade atribui importância ao exercício desta forma, que nada mais é que o tratado. Ao invés de se antecipar como sistema, o tratado pode ser didático no tom, mas jamais recorre aos instrumentos "coercitivos da demonstração matemática", porque a quintessência de seu método é a representação.

Se o método cartesiano é aquele que nega os objetos do mundo em prol da afirmação da subjetividade racional, Benjamin propõe uma inversão a esta concepção, no momento em que defende o método como desvio ou caminho indireto. A crítica benjaminiana ao método científico moderno fica clara, principalmente como contraponto à descrição de método feita por Descartes:

${ }^{6}$ BACON, F. Ensaios. Lisboa: Guimarães Editores, 1992, p.173.

7 BENJAMIN, W. Origem do Drama Barroco Alemão. São Paulo: Brasiliense, 1984, p. 49. 
Por método eu entendo as regras certas e fáceis, graças às quais todos os que as observam exatamente jamais tomarão como verdadeiro aquilo que é falso e chegarão, sem se cansar com esforços inúteis, ao conhecimento verdadeiro do que pretendem alcançar ${ }^{8}$.

Ao se afastar desta concepção cartesiana, Benjamin procura um pensamento marcado por frequentes interrupções, para renovar contato com os objetos, em vez de esquecê-los. Se a perspectiva da razão iluminista assegura esquemas apartados dos elementos históricos, Benjamin quer por em jogo novamente as relações historicamente concretas ou os pormenores do conteúdo material.

\footnotetext{
Incansável, o pensamento começa sempre de novo, e volta sempre, minunciosamente, às próprias coisas. Esse fôlego infatigável é a mais autêntica forma de ser da contemplação. Pois ao considerar um mesmo objeto nos vários estratos de sua significação, ela recebe um estímulo para o recomeço perpétuo e uma justificação para a intermitência do seu ritmo ${ }^{9}$.
}

Da mesma forma que o mosaico que lida com fragmentos e interrupções, a contemplação do pensamento justapõe elementos isolados e heterogêneos. Neste sentido, Benjamin defende o tratado e o ensaio como formas privilegiadas de escrita filosófica, pois não se afastam do próprio mundo sensível sobre o qual refletem. Neste modo de construção do texto filosófico, existe um jogo de diferenças mútuas, totalmente desvinculado do "preceito doutrinário imperativo". Isto implica dizer que a representação da verdade desdobra-se a partir de um método que se distancia de pretensões científicas definitivas, em prol da construção de uma história aberta a atualizações. Os objetos não possuem uma identidade fixa ou acabada, pois são como fragmentos, caóticos e irradiadores, que compõem o real.

Enquanto Descartes denuncia tais fragmentos do mundo como desordem, como o perecível, como mera aparência, que deve ser enfrentada pela Razão, Benjamin propõe uma noção de imagem dialética que está a meio caminho entre o sensível e o inteligível. O método do desvio benjaminiano restitui à aparência seu caráter de conhecimento.

Já a concepção kantiana de experiência implica o conhecimento de um objeto que se produz somente pelo fato de que as percepções sensíveis são sintetizadas de acordo com uma regra geral (categoria). No início da Crítica da Razão Pura, Kant empreende uma divisão geral entre juízos analíticos e sintéticos. Os juízos analíticos

8 DESCARTES, R. Regras para a direção do espírito. Porto: Edições 70, 1985, p. 42.

9 BENJAMIN Opus Cit., p. 50. 
independem da experiência e são a priori. Os juízos sintéticos são os que derivam da experiência ou que dela dependem, ou seja, são a posteriori.

Se a experiência, para Kant, é um conjunto de juízos sintéticos a posteriori, a matemática, a ciência pura da natureza e a metafísica são constituídas por juízos a priori, ou seja, por nexos que a razão estabelece por virtude própria e com absoluta necessidade, sem fundamento na experiência. Para Kant, não é o sujeito que gravita em torno dos objetos, mas os objetos são apreendidos pelo sujeito como fenômenos. Trata-se de uma inversão no processo de conhecimento, pois aquilo que pode ser conhecido pelo sujeito é o conceito da coisa, ou seja, o conceito mediado por categorias a priori do entendimento.

Com base neste procedimento, Kant estabelece as condições de possibilidade de toda e qualquer experiência. As formas a priori (espaço e tempo) e os conceitos puros do entendimento ou categorias estabelecem as condições da experiência possível e são elas que determinam os limites do conhecimento. A reflexão de Kant concentra-se na análise das condições que possibilitam o conhecimento. Na introdução de sua Crítica da Razão Pura, Kant deixa claro sua busca por fundamentos para a experiência. "Embora todo o nosso conhecimento comece com a experiência, nem por isso todo ele se origina justamente da experiência"10.

No texto Sobre um programa da filosofia do futuro (1918), Benjamin propõe uma crítica ao sistema de Kant, a partir do alargamento do conceito de experiência. Neste escrito contemporâneo à tese de doutoramento $O$ conceito de crítica de arte no romantismo alemão (1917-1919), Benjamin aponta tarefas e desafios para um programa de uma filosofia vindoura. Além da crítica ao sistema kantiano, sua intenção era também criticar o lluminismo, colocando em evidência suas limitações.

Ao tomar as reflexões kantianas como ponto de partida, Benjamin procura novas formulações e problemas para a filosofia. Para Benjamin, antes de negar a filosofia kantiana como um todo, era necessário descobrir quais elementos deveriam ser realmente modificados e quais mereciam ser descartados.

É da maior importância para a filosofia vindoura reconhecer e distinguir que elementos do pensamento kantiano tem que ser assimilados e

\footnotetext{
${ }^{10}$ KANT, I. "Crítica da razão pura". In: Os pensadores - Vol. I. São Paulo: Nova Cultural, 1987, p. 1.
} 
desenvolvidos, quais tem de ser modificados e quais devem ser rechaçados ${ }^{11}$.

$\mathrm{Na}$ investigação do pensamento kantiano, Benjamin argumenta que a exigência principal para uma filosofia do futuro seria elaborar fundamentos epistemológicos de um conceito superior de experiência. Segundo Benjamin, isso pressupõe a criação de um novo conceito de conhecimento e uma nova representação do mundo. Para Kant, o conhecimento e a experiência verdadeiros são elaborados a partir de conceitos a priori no sujeito. Para Benjamin, a verdade produzida pela experiência não pode ser traduzida em conceitos porque não é resultado de processos de abstração.

O esforço de compreensão de Benjamin acerca do pensamento kantiano constitui a busca de Benjamin por uma nova concepção de experiência, que revela sua intenção de definir e distinguir algo qualitativamente distinto do que se apresentava ao indivíduo moderno, sujeito pobre de experiência, como posteriormente ele aprofunda em Experiência e Pobreza (1933).

Em Sobre um Programa para uma Filosofia Futura, Benjamin aponta que Kant ignorou que todo o conhecimento filosófico tem sua expressão na linguagem e não em fórmulas e números, semelhante à matemática. É a linguagem que pode afirmar a supremacia da filosofia futura. $O$ conceito resultante da reflexão sobre a linguagem do conhecimento pode criar uma noção de experiência, que o ordenamento sistemático kantiano não conseguiu estabelecer.

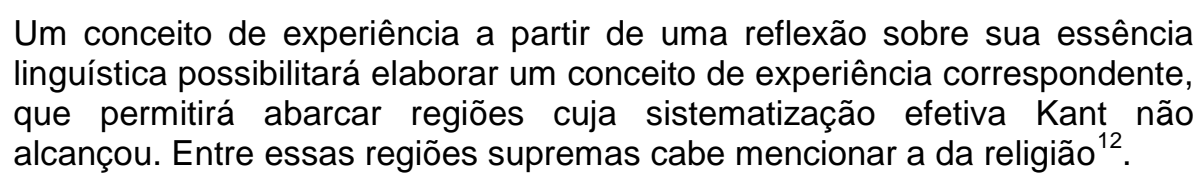

A afirmação de que o conhecimento filosófico tem sua expressão na linguagem e não em fórmulas e números também será colocada posteriormente na Origem do Drama Barroco Alemão. Embora Benjamin afirme que a filosofia por vir deveria estar alicerçada nas bases do pensamento kantiano, ele se afasta dessa ideia, ao argumentar que o método é caminho indireto e desvio, abrindo espaço para a possibilidade da citação e do fragmento.

\footnotetext{
${ }^{11}$ BENJAMIN, W "Sobre el Programa de la Filosofia Futura". in: Sobre el Programa de La Filosofia Futura y otros ensayos. Caracas: Monte Avila Editores, 1970, p. 9.

12 Idem, p. 16.
} 
Entre os diversos escritos de Benjamin, talvez o que mais represente esta noção de fragmento seja o trabalho das Passagens, que afirma essa busca por uma não sistematicidade filosófica, que implica uma aproximação com a dimensão da linguagem filosófica. No texto Sobre um Programa da Filosofia do Futuro, a expressividade da linguagem possibilita outra experiência, que abarca a história. Por pertencer ao lluminismo, Kant defendia a onipotência da razão em prol do progresso da história e da humanidade. No célebre texto O que é lluminismo? (1784), Kant responde à indagação da seguinte forma:

Esclarecimento é a saída do homem da sua menoridade de que ele próprio é culpado. A menoridade é a incapacidade de se servir do entendimento sem a orientação de outrem. Tal menoridade é por culpa própria, se a sua causa não residir na carência de entendimento, mas na falta de decisão e de coragem em se servir de si mesmo, sem a guia de outrem ${ }^{13}$.

Para a construção de uma Filosofia da História, Benjamin critica a noção de progresso iluminista, especialmente nas teses Sobre o Conceito da História. Ele interpreta a obra Ângelus Novus, de Paul Klee, ao qual compara com a representação do anjo da História, que parece querer aproximar-se de algo que encara de forma fixa, para salvar os fragmentos significativos do passado:

O anjo da história deve ter esse aspecto: seu rosto está dirigido para o
passado. Onde nós vemos uma cadeia de acontecimentos, ele vê uma
catástrofe única, que acumula incansavelmente ruína sobre ruína e as
dispersa a nossos pés. Ele gostaria de deter-se para acordar os mortos e
juntar os fragmentos. Mas uma tempestade sopra do paraíso e prende-se
em suas asas com tanta força que ele não pode mais fechá-las. Esta
tempestade o impele irresistivelmente para o futuro, ao qual ele vira as
costas, enquanto o amontoado de ruínas cresce até o céu. Essa
tempestade é o que chamamos progresso ${ }^{14}$.

$\mathrm{Na}$ tese, Benjamin atribui a causa da catástrofe histórica à passividade de um povo, ao conformismo gerado em parte pelo desenvolvimento avassalador da técnica. Essa produz o conforto e o bem-estar dando a impressão de que a realização da história é propalada pela "consciência iluminista" e a consequente "perfectibilidade" do gênero humano.

Desta maneira, a formulação filosófica benjaminiana de um conceito mais pleno e até mesmo total de experiência passa pela crítica ao progresso da história e por uma revisão da filosofia kantiana. Trata-se da primeira tentativa de Benjamin em

\footnotetext{
${ }^{13}$ KANT Opus Cit., p. 1.

${ }^{14}$ BENJAMIN, W. Obras Escolhidas 1: Magia e Técnica, Arte e Política. São Paulo: Brasiliense, 1994, p.162.
} 
determinar e elaborar um projeto filosófico que fosse capaz de recuperar o verdadeiro sentido da experiência, para se sobrepor àquela outra da sociabilidade burguesa, que é distanciada da tradição. 


\section{REFERÊNCIAS}

AGAMBEN, G. Infância e História: destruição da experiência e origem da história. Belo Horizonte: UFMG, 2005.

ARISTÓTELES. Metafísica. São Paulo: Abril, 1973.

BACON, F. Ensaios. Lisboa: Guimarães Editores, 1992.

BENJAMIN, W. Obras Escolhidas 1: Magia e Técnica, Arte e Política. São Paulo: Brasiliense, 1994.

Paulo: Editora 34, 2002.

Reflexões sobre a criança, o brinquedo e a educação. São Origem do Drama Barroco Alemão. São Paulo: Brasiliense, 1984. . "Sobre el Programa de la Filosofia Futura". in: Sobre el Programa de La Filosofia Futura y otros ensayos. Caracas: Monte Avila Editores, 1970.

DESCARTES, R. Regras para a direção do espírito. Porto: Edições 70, 1985.

HUME, D. Investigações acerca do entendimento humano. Rio de Janeiro: Companhia Editora Nacional; São Paulo: Edusp, 1972.

KANT, I. "Crítica da razão pura". In: Os pensadores - Vol. I. São Paulo: Nova Cultural, 1987.

“O que é lluminismo?” In: Textos Seletos. Petrópolis: Vozes, 1985.

PLATÃO. A República. São Paulo: Nova Cultural, 1997. 